\title{
Evidence of African Swine Fever Virus in Pigs Slaughtered at Muhanzi Municipal Abattoir in Bukavu City, Eastern of Democratic Republic of Congo
}

\author{
Bisimwa Ntagereka Patrick, Wasso Shukuru Dieudonné, Ntakundi Muderhwa Théophile, \\ Bwihangane Birindwa Ahadi, Bisimwa Basengere Espoir, Mushagalusa Nachigera Gustave, \\ Katcho Karume, Baluku Bajope
}

Department of Animal Science and Production, Université Evangélique en Afrique, Bukavu, Democratic Republic of Congo

Email address:

pat.bisimwa@yahoo.com (B. N. Patrick)

\section{To cite this article:}

Bisimwa Ntagereka Patrick, Wasso Shukuru Dieudonné, Ntakundi Muderhwa Théophile, Bwihangane Birindwa Ahadi, Bisimwa Basengere Espoir, Mushagalusa Nachigera Gustave, Katcho Karume, Baluku Bajope. Evidence of African Swine Fever Virus in Pigs Slaughtered at Muhanzi Municipal Abattoir in Bukavu City, Eastern of Democratic Republic of Congo. International Journal of Microbiology and Biotechnology. Vol. 4, No. 1, 2019, pp. 1-7. doi: 10.11648/j.jimb.20190401.11

Received: December 14, 2018; Accepted: January 2, 2018; Published: February 19, 2019

\begin{abstract}
African swine fever (ASF) is an acute, highly infectious and fatal arboviral disease affecting both wild and domestic pigs causing a very high mortality rate that goes up to $100 \%$. Up to date no vaccines are available to protect the animals against the disease. No study has been conducted to assess the presence of ASFV in imported slaughtered pigs in Bukavu city and very limited literature is available on ASF in the entire country of Democratic Republic of Congo. A cross sectional study was carried out in Muhanzi municipal abattoir of Bukavu city, eastern Democratic Republic of Congo to investigate the presence of antibodies against African swine fever virus (ASFV) and the viral genome in imported pigs for slaughtering. The commercial enzyme-linked immunosorbent and the conventional polymerase chain reaction assays were used to screen both ASFV antibodies and viral genome respectively. In total 284 pigs were tested out of which $87.3 \%$ (248/284) were female adult of more than 1 year old. The majority of them $(75.4 \%(214 / 284)$ were imported from Rwanda of which about $62.7 \%(178 / 284)$ of them presented clinical sign such as redness in the skin. Most of them (90.8\%) were exotic breed. Out of 284 animals tested, ASFV antibodies were detected in 69 giving an overall seroprevalence of $24.2 \%$ from which pigs originated from Idjwi territory were more ASF seropositive (64.2\%) compared to the one imported from Rwanda (11.2\%). The seropositivity was found to be significantly associated with the breed $(\mathrm{OR}=7.4, \mathrm{p}<0.05)$, origin of animals $(\mathrm{OR}=14.2$, $\mathrm{p}<0.05)$ as well as all the observed clinical signs $(\mathrm{p}<0.05)$ except nasal discharges and abnormal liver ( $>0.05)$. Additionally, 38 animals out of 284 tested (13.3\%) were ASFV PCR positive with high infectivity rate $(35.7 \%)$ when pigs slaughtered originated from Idjwi territory of the DRC were found to be more infected than the one imported from $\mathrm{Rwanda}(\mathrm{OR}=8.5$, $\mathrm{p}<0.05)$. The ASFV PCR positivity was found to be significantly associated with age where young animals $(<12$ months old) were found to be more infected $(\mathrm{OR}=3.6, \mathrm{p}<0.05)$. Similarly, the local breeds were found to be significantly more infected when compared with exotic breed (OR-7.6; $<<0.0001)$. Deliberate policy has to be implemented in order to prevent spread of the disease to pig farms within the region and for saving the pig industry from ASF devastation.
\end{abstract}

Keywords: Diagnosis, African Swine Fever, Slaughtered Pigs, Prevalence, Bukavu City

\section{Introduction}

African swine fever (ASF) is a DNA virus disease associated with argasid ticks and wild suidsinfecting domestic pigs, and leading to a rapidly lethal disease. The causative agent is African swine fever virus (ASFV) [1] which is an enveloped double stranded DNA virus of the As farviridae family [2]. Depending on the pig breed, a range of outcomes has been reported varying from acute to chronic disease [3]. Symptoms such as high fever, haemorrhages in internal organs and the skin and death within three to ten days have also been observed [2]. It is considered as the most 
limiting factor of pig production in Africa because of the high mortality associated with it, but also because farmers are discouraged to invest in pig production because of the fear of it $[4,5]$. Hosts demonstrating the disease include domestic pigs (Sus domestica), European wild boar, and American wild pigs. Ticks of the genus Ornithodoros are considered the natural arthropod host and some speculations show that ASFV is a virus of arthropods and that mammalian species, such as domestics wine, represent "accidental hosts" [6]. Some changes have been reported in the epidemiology and distribution of ASF during the 1990s and 2000s where by the African Swine Fever Virus was detected in regions not naturally affected by ASF including West African countries, where the virus was first reported in Cote d'Ivoire (1996), Nigeria (1997), Togo (1997), Ghana (1999), Burkina Faso (2003) and recently, Chad (2010). The disease was also reported in some islands including Madagascar in year 1998 and Mauritius in 2007 [7].

The ASFV penetration into pigs occurs normally either orally or nasally, although other routes such as cutaneous, subcutaneous, or scarification has also been reported. Once the disease is established in an area, it mainly spreads [8]. The ASF transmission is either by direct contact with infected animals or indirect by contact with fomite or substances like furniture, clothing, bedding, or feed contaminated by material having virus such as blood, urine from infected pig. It has been reported that the virus can also be transmitted mechanically by blood-sucking insects such as mosquitoes and biting flies [9]. Early detection of the ASF is required to prevent the spread of the disease [10]. However, its clinical diagnosis is difficult because of (i) the wide range of clinical forms and the disease's complex epidemiology, and (ii) the fact that its symptoms are similar to those of other viral infections such as CSF, PRRS, swine erysipelas, salmonella, Porcine Dermatitis and Nephropathy Syndrome, as well as other septicaemic conditions such as poisoning [8]. Hence, rapid laboratory diagnosis is essential and it should involve the detection and identification of the virus particles and the specific anti-ASFV antibodies [11]. To date, 24 distinct ASFV genotypes ( I - XXIV) have been reported based on the P72 genotyping and most of them are circulating in Sub-Saharan Africa, [12, 13, 14] while only 2 of them mainly genotypes I and II are known to spread outside Africa [1]. Currently the prevention and control of ASF is still challenging since there is no efficient vaccine for this disease. The prevention methods used currently are stamping out as well strict respect of biosecurity measures [9]. Challenges mainly rely on the complexity of the virus, with genes involved in the evasion of the immune response and the lack of an effective protection mediated by neutralizing antibodies [15] making the conventional formulations of live and inactivated vaccines that work with the majority of pathogens inefficient as protection against ASFV.

The Democratic Republic of Congo has registered the highest ASFV outbreaks (84) out of 14 countries and a loss of 105,614 swine in 2011 [16]. Despite the evidence of ASF in the DRC and the variety of genotypes reported in surrounding countries, studies so far conducted haven't covered the entire country. South Kivu, located in the eastern part of DRC, has been at the heart of conflicts and wars in DRC leading to important losses of livestock [17]. As result, a lot of animal importation including pigs is reported in the region since farmers are discouraged to invest in pig production fearing to experience again animal losses during wars. Pigs are imported from surrounding countries mainly Rwanda, and Idjwi territory neighbour to Rwanda and are sold and slaughtered at the Muhanzi Municipal Abattoir in Bukavu city. However their healthy status is unknown and can therefore be a source of contamination for other pigs domesticated by local farmers in the region. This study aimed at evaluating the presence of African swine fever in pigs, which are brought at Muhanzi Municipal Abattoir either for sale or slaughter by detecting both ASFV antibodies and the viral genome.

\section{Methodology}

\subsection{Study Site}

A multiple time cross-sectional survey was carried out at Muhanzi municipal abattoir from April to June 2017to collect both blood and serum samples from slaughtered pigs. This abattoir constitutes the main pig slaughterhouse in the city but also a main site where all imported pigs for sell or slaughtering are stocked. Pigs are coming from Idjwi territory (in DRC) and Rwanda. It islocated in Bukavu city, the capital city of the South Kivu province located in the Eastern of the Democratic Republic of the Congo (DRC). This city lies at the extreme south-western edge of Lake $\mathrm{Kivu}$, west of Cyangugu in Rwanda from which it is separated by the outlet of the Ruzizi River. Bukavu city lies between latitude $2^{\circ} 30^{\prime} 55^{\prime \prime}$ South and longitude $28^{\circ} 50^{\prime} 42^{\prime \prime}$ East with an elevation of $1498 \mathrm{~m}$. As of 2016, Bukavu city had an estimated population of 870,954 . It covers an area estimated to $60 \mathrm{~km}^{2}$ and is known as one of the most densely populated areas of the Democratic Republic of the Congo. The average annual temperature is $19.9^{\circ} \mathrm{C}$, and annual precipitation levels measure about 54.76 inches $(1,391 \mathrm{~mm})$. Itis an important transport hub and gateway to eastern DR Congo. Its proximity to the LakeKivu that connectsIdjwi territory to Bukavu city.

\subsection{Study Population and Sample Size}

The target population in this study was pigs brought at Muhanzi Municipal Abattoir either for sale or slaughter. All adult pigs of more than one year old, of both female and male were sampled. A total of 284 animals were successfully selected for sampling in this study using 5\% level of precision at $95 \%$ confidence level following the formula as previously described [18]: $\mathrm{n}=\mathrm{Z}^{2} \mathrm{X} \mathrm{P}(1-\mathrm{P}) / \mathrm{d}^{2}$, where $\mathrm{n}=$ Sample size, $\mathrm{Z}=1.96$ at $95 \%$ confidence level, $\mathrm{P}=$ is the estimated prevalence which is most conservatively estimated to be $76 \%$ considering that there is no reliable prevalence 
data for African swine fever in the city, $d=$ Standard error (taken as $5 \%$ ).

\subsection{Sample Collection}

The plain vacutainer tubes were used to collect about 3-5 $\mathrm{ml}$ of blood aseptically from the jugular vein after slaughtering from all pigs. This blood was used to obtain serum for serological analysis after centrifugation at 3000rpm for 10 minutes. Similarly, the whole blood sample was collected into vacutainer tubes with EDTA (anticoagulant) and that was used for PCR assay. After collection, all serum and blood samples collected were transported on ice to the molecular biology laboratory of Evangelical University in Africa (UEA) and stored at $-20^{\circ} \mathrm{C}$ before analysis.

\subsection{Serological Analysis for ASFV Antibody Detection}

The indirect enzyme-linked immunosorbent assay (ELISA) assay was used to detect ASFV antibody using SVANOVIR ASFV-At kit, (ALGENEX Madrid, Spain) as per manufacturer's instructions. Briefly, $100 \mu$ l of diluted controls as well as samples were added to the microtiter plates (96 wells) (Maxisorb, Nunc, Denmark) coated with non-infectious ASFV p30 as detection antigen followed an incubation at $37^{\circ} \mathrm{C}$ for 1 hour. Horseradish peroxidase conjugated anti-swine antibody as well as substrate solution were added to each well after washing steps with PBS-Tween 20 and the reaction was stopped by addition of a stop solution in each well. Optical density (OD) values werethen determined at $450 \mathrm{~nm}$ in the microplate reader (Biotek synergy HT, US) machine before calculating the percentage positivity (PP) for each tested sample using the formula described in the protocol. Any sample with a $\mathrm{PP} \leq 10$ was considered to be negative, while a sample with $\mathrm{PP}>10$ was considered positive.

\subsection{DNA Extraction and PCR Amplification}

Viral DNA was extracted directly from $200 \mu$ l aliquots of blood using DNeasy Blood and Tissue Kit (Qiagen, USA) following manufacturer's recommendations. The integrity of the extracted g DNA was check on $0.8 \%$ gel electrophoresis while the quality and quantity were assessed by Nano drop electro photometer. To confirm the presence of the ASFV nucleic acid, a $257 \mathrm{bp}$ region corresponding to the $\mathrm{C}$-terminal region of the $P 72$ major capsid protein encoding for $\mathrm{B} 646 \mathrm{~L}$ gene was amplified using the diagnostic primers: PPA1, 5AGTTATGGGAAACCCGACCC-3; and PPA2, 5CCCTGAATCGGAGCATCCT-3) as reported in previous study [19]. All reactions were performed in a total volume of $25 \mu \mathrm{l}$ containing $1.25 \mu \mathrm{M}$ of each primer, One Taq 2xMasterMix with Standard buffer (New England Biolabs), which contains $(1.8 \mathrm{mM} \mathrm{MgCl} 2,0.2 \mathrm{mMdNTPs}, 25$ units $/ \mathrm{ml}$ One taq DNA polymerase, 20mMTris-Hcl) and additional $2.5 \mathrm{mM}$ of $\mathrm{MgCl}_{2}$ was added. DNA was amplified at $95^{\circ} \mathrm{C}$ for 10 minutes as initial denaturation followed by 40 cycles of denaturation at $95^{\circ} \mathrm{C}$ for 15 seconds, annealing at $62^{\circ} \mathrm{C}$ for 30 seconds and extension at $72^{\circ} \mathrm{C}$ for 30 seconds. These cycles followed by an extension step of $72^{\circ} \mathrm{C}$ for 7 minutes. PCR products were separated by gel electrophoresis on a $2 \%$ agarose gel stained with GelRed nucleic acid stain and visualized by UV light.

\subsection{Data Analysis}

Statistical analysis was conducted using CDC Epi-info ${ }^{\mathrm{TM}}$ version 7 (Centers for Disease Control and Prevention, 2016). The descriptive statistics (frequencies) were carried out to describe the physical characteristics of domestic pigs tested before and after slaughter ring. The odds ratio and statistical significance between sero-positive and seronegative slaughtered pigs were calculated using Chi-square test for discrete variables at the $95 \%$ confidence level. This test allowed on one hand to associate the seropositivity results with the clinical signs and on the other hand the seroprevalence of pigs with their age, breed, origin, and sex.

\section{Results}

\subsection{Characteristics of Pigs Tested}

Most of tested pigs were female $(87.3 \%)$ of more than one year old (67.3\%) imported from Rwanda (75.4\%) from which $(62.7 \%)$ presented the redness in the skin, having challenges to move $(12.7 \%)$, thickness $(10.9 \%)$, nasal discharges (8.5\%), abnormal spleen (8.0\%), high fever (5.9\%), and abnormal liver $(4.9 \%)$. Only few local breeds were counted among them $(9.2 \%)$, the majority of pigs being of improved breed $(90.8 \%)$. The summary on the characteristics of pigs on which samples were collected are presented in table 1.

Table 1. Physical characteristics of domestic pigs tested before and after slaughtering.

\begin{tabular}{llll}
\hline Variables & Characteristics & $\mathbf{N}^{\mathbf{0}}$ of pigs & Percentage (\%) \\
\hline \multirow{2}{*}{ Sex } & M & 36 & 12.7 \\
& F & 248 & 87.3 \\
Age & Adult (>1 year) & 191 & 67.3 \\
& Young (<1 year) & 93 & 32.8 \\
Breed & Local & 26 & 9.2 \\
& Imported & 258 & 90.8 \\
Origin & Rwanda & 214 & 75.4 \\
& Idjwi & 70 & 24.6 \\
Physical & Thinness & 31 & 10.9 \\
aspects & Redness in skin & 178 & 62.7 \\
& Nasal discharges & 24 & 8.5 \\
& Challenge to move & 36 & 12.7 \\
& High fever & 15 & 5.9 \\
& Abnormal spleen & 23 & 8.0 \\
& Abnormalliver & 14 & 4.9 \\
\hline
\end{tabular}

\subsection{Detection of ASFV Antibody and Viral Genome in Slaughtered Pigs}

Out of 284 animals tested for the presence of antibodies against ASFV, 69 were positive giving a seroprevalence of $24.2 \%$ from which, pigs originated from Idjwi territory were more ASF seropositive $(64.2 \%)$ compared to the ones imported from Rwanda (11.2\%) (Table 2). Additionally, a 
discrete band of $257 \mathrm{bp}$ related to the c-terminal region relative to the $\mathrm{B} 464 \mathrm{~L}$ gene of the virus genome was amplified in 38 animals out of the 284 tested using diagnostic primers (PPA1 and PPA2) (Figure 1). Among them, pigs from Idjwi were more infected $(35.7 \%)$ than the one originated from Rwanda (6.07\%) (Table 2).

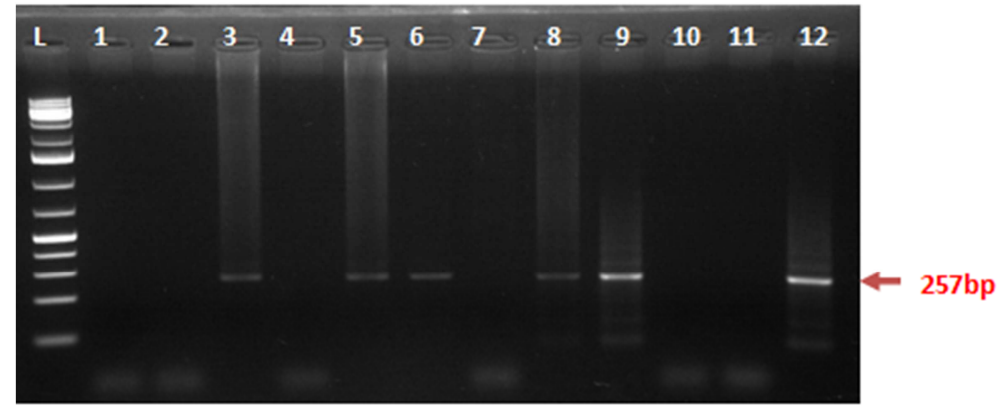

Figure 1. The 2\% agarose gel image showing PCR positive samples. Line 1-10: test samples; NC: Negative control and PC: positive control. Samples 3, 5, 6, 8 and 9 are positives, while samples 1,2, 4, 7 and 10 are negatives.

Table 2. Proportion of ELISA and PCR positive slaughtered pigs at Muhanzi slaughterhouse, Bukavu City according to their origin.

\begin{tabular}{lllllll}
\hline Origin of pigs & No pigs tested & Proportion (\%) & ELISA positives & Proportion (\%) & PCR Positives & Proportion (\%) \\
\hline Rwanda & 214 & 75.4 & 24 & 11.2 & 13 & 6.07 \\
Idjwi (DRC) & 70 & 24.6 & 45 & 64.2 & 25 & 35.7 \\
Total & 284 & 100 & 69 & 24.2 & 38 & 13.3 \\
\hline
\end{tabular}

With respect to ASFV seroprevalence, the largest proportion of seropositivitity using ELISA assay was recorded on female pigs $(24.6 \%)$, adults $(25.1 \%)$, of local breed $(65.3 \%)$ originated from Idjwi (64.2\%). The detection of ASFV by ELISA assay was found to be significantly associated with the breed $(\mathrm{OR}=7.4, \mathrm{p}<0.0001)$ and origin of animals $(\mathrm{OR}=14.2, \mathrm{p}<0.0001)$ while the association was not significant according to the $\operatorname{sex}(\mathrm{OR}=1.1, \mathrm{p}=0.38)$ and age of pigs $(\mathrm{OR}=1.15, \mathrm{p}=0.32)(\mathrm{Table} 3)$.

Table 3. Seroprevalence-specific rates of ASF in pigs by sex, age, breed and origin.

\begin{tabular}{|c|c|c|c|c|c|c|}
\hline Variable & Category & $\mathbf{N}^{0}$. pigs sampled & No. of ELISA+ve & Proportion & OR $(95 \%$ CI $)$ & P value \\
\hline \multirow[t]{2}{*}{ Sex } & Female & 248 & 61 & 24.6 & \multirow{2}{*}{$1.1(0.49-2.63)$} & \multirow{2}{*}{0.38} \\
\hline & Male & 36 & 8 & 22.2 & & \\
\hline \multirow[t]{2}{*}{ Age } & Adult (>12months) & 191 & 48 & 25.1 & \multirow{2}{*}{$1.15(0.64-2.06)$} & \multirow{2}{*}{0.32} \\
\hline & Young ( $<12$ months) & 93 & 21 & 22.6 & & \\
\hline \multirow[t]{2}{*}{ Breed } & Local & 26 & 17 & 65.3 & \multirow{2}{*}{$7.4(3.1-17.7)$} & \multirow{2}{*}{$<0.0001$} \\
\hline & Exotic & 258 & 52 & 20.1 & & \\
\hline \multirow[t]{2}{*}{ Origin } & Rwanda & 214 & 24 & 11.2 & \multirow{2}{*}{$14.2(7.45-27.22)$} & \multirow{2}{*}{$<0.0001$} \\
\hline & Idjwi (DRC) & 70 & 45 & 64.2 & & \\
\hline
\end{tabular}

\subsection{Clinical Signs Associated with ASFV Seropositivity}

After analysing the clinical signs of pigs tested, and ASF seropositivity, significant associations were found between all observed clinical signs and ASFV seropositivity $(\mathrm{p}<0.05)$ except nasal discharges and abnormal liver $(\mathrm{p}>0.05)$ ( Table 4).

Table 4. Association of ASFV clinical signs observed on tested pigs with seropositivity.

\begin{tabular}{lllll}
\hline Clinical signs & $\begin{array}{l}\text { Seropositives } \\
\mathbf{N}(\mathbf{\%})\end{array}$ & $\mathbf{X}^{\mathbf{2}}$ & $\mathbf{9 5 \%} \mathbf{C I}$ & P-value \\
\hline Thinness & $3(9.7)$ & 3.2 & $0.08-1.03$ & 0.018 \\
Redness in skin & $53(29.8)$ & 7.01 & $1.2-4.4$ & 0.0023 \\
Nasal discharges & $6(25)$ & 0.007 & $0.3-2.7$ & 0.454 \\
Challenge for moving & $3(8.3)$ & 4.7 & $0.07-0.8$ & 0.005 \\
High fever & $8(53.3)$ & 3.1 & $1.01-8.3$ & 0.028 \\
Abnormal spleen & $12(52.2)$ & 8.9 & $1.6-9.3$ & 0.0014 \\
Abnormalliver & $6(42.9)$ & 1.8 & $0.8-7.3$ & 0.061 \\
\hline
\end{tabular}

\subsection{Factors Associated with ASFV Positivity}

Based on PCR assay results, the largest proportion of ASFV positive pigs was recorded on females (14.1\%), adults $(17.2 \%)$ majority of local breed (46.1\%) most of them originated from Idjwi (35.7\%). The ASFVPCR positivity was found to be significantly associated with age where by young animals $(<12$ months old $)$ were found to be more infected $(\mathrm{OR}=3.6, \mathrm{p}=0.00323)$ when compared with the adult pigs. Similarly, a significant association of ASFV positivity with breed and origin of the pigs were identified where local breed were more infected when compared with exotic breed (OR7.6; $\mathrm{p}<0.0001)$ and pigs slaughtered originated from Idjwi territory of the DRC were found to be more infected than the ones imported from Rwanda $(\mathrm{OR}=8.5, \mathrm{p}<0.0003)$ (Table 5). However no significant association was found between ASFV positivity and sex of pigs. 
Table 5. Logistic regression for parameters associated with ASFV positivity in slaughtered pigs DR. Congo.

\begin{tabular}{|c|c|c|c|c|c|c|}
\hline Variables & Category & $\mathbf{N}^{0}$. pigs sampled & $\mathrm{N}^{0}$. Of PCR+ve & Proportion & OR $(95 \% \mathrm{CI})$ & P value \\
\hline \multirow{2}{*}{ Sex } & Female & 248 & 35 & 14.1 & - & \\
\hline & Male & 36 & 3 & 8.3 & $1.8(05-6.2)$ & 0.254 \\
\hline \multirow[t]{2}{*}{ Age } & Adult (>12months) & 191 & 33 & 17.2 & - & \\
\hline & Young ( $<12$ months) & 93 & 5 & 5.3 & $3.6(1.3-9.6)$ & 0.00323 \\
\hline \multirow[t]{2}{*}{ Breed } & Exotic & 258 & 26 & 10.1 & & \\
\hline & Local & 26 & 12 & 46.2 & $7.6(3.2-18.2)$ & $<0.0001$ \\
\hline \multirow[t]{2}{*}{ Origin } & Rwanda & 214 & 13 & 6.07 & - & \\
\hline & Idjwi (DRC) & 70 & 25 & 35.7 & $8.5(0.05-0.3)$ & $<0.0001$ \\
\hline
\end{tabular}

\section{Discussion}

In this study the OIE recommended diagnostic assays such as PCR and ELISA were used to detect the presence of ASFV in slaughtered pigs at Muhanzi municipal abattoir in Bukavu city. A high ASFV seroprevalence of $24.2 \%$ was found by ELISA assay. Additionally the higher prevalence of ASFV obtained in our study compared to studies conducted in farm level [20] may be due to the fact that farmers probably recognize ASF symptoms at an early stage and rapidly bring animals to the slaughter house for sale [21]. This evidence was supported by a considerably higher ASFV prevalence found in apparently healthy animals sampled at slaughterhouse, than in the farm pig population [22].

This seroprevalence obtained in this study is strikingly different from the ones of similar studies conducted in Uganda where a seroprevalence of $52.96 \%$ was obtained in slaughter pigs over a one-year period [23] which is higher than the one obtained in the current study. In addition, the seroprevalence obtained for this study was higher than the one reported in slaughtered pigs in Mubende district $(0.2 \%)$, in central Uganda district $(0 \%)$ as well as in an abattoir in Senegal $(13.9 \%)$ [24, 25]. However, the seroprevalence results from this investigation are in contrast with previous studies conducted in central Uganda district [3] and in Madagascar, [25] where all slaughtered pigs tested were ELISA negative.

These differences in ASF prevalence can be attributed to the differences in geographical aspects about the provenance of the pigs as well as the study period. Pigs from which blood samples were collected in this study were from different geographical origins compared to the ones tested in the mentioned studies in Uganda. Additionally, the study conducted in Uganda [23] was for a period of 12 months in slaughter domestic pigs while the current study was of a shorter period of time (3 months). Furthermore, a very low sample size (39 porcine serum samples) [3] was used compared to the one used for this study (284 samples). It is known that the presence of ASF specific antibodies is indicative of previous infection [26], and given that antibodies are produced from the first week of infection and persist for long periods they are appropriate markers for the diagnosis of the disease [27]. The overall ASFV prevalence determined by PCR among the slaughtered pigs sampled was estimated to $13.3 \%$ which is close to the one observed in Uganda [23] that revealed a prevalence of $11.5 \%$ over a one year period. These results are an evidence of infection among slaughtered pigs in the study region. A study has been conducted in the same countries using the same molecular technique and a PCR positivity rate of $100 \%$ was found among farm pigs from which blood samples were collected and tested [28]. This very high prevalence could be due to the types of assay used, (Real-time PCR), which is more sensitive than the conventional PCR abut also the study was conducted during an ASFV outbreak periods. The higher prevalence of ASFV antigen positive pigs obtained in this study allows assuming that there was no effect of temperature differences from field collection sites during transportation to the laboratory, which could probably have degraded the viral DNA. Furthermore, the PCR results obtained from this study were different from a recent study conducted along the Kenya-Uganda border where no sample has been found to be PCR positive out of 1107 pig blood sample tested [20]. A study carried out in south-western Kenya [29] has demonstrated that some ASFV infected pigs were positive with ASFV from blood, but appeared asymptomatic. However, in the case of our study ASFV seropositivity was significantly associated with all observed clinical signs (redness in skin, challenge for moving, high fever, and abnormal spleen) except nasal discharges and abnormal liver. Our results showed that the detection of ASFV was found to be significantly associated with the breed and origin of animals. A different result has been found in Madagascar [25] showing that risk factors associated with the ASF are the breeding system and alimentation of animals. That difference in risk factors associated with the disease can be justified by the fact that his study was conducted at farmer level while ours was conducted at the slaughterhouse.

The presence of infected pigs at Muhanzi Municipal abattoir is of particular importance to the control of ASF. Previous studies have identified the movement of infected pigs to an abattoir and the movement of infected pork products as being major risk factor for outbreaks, which appear to be distinct from the sylvatic cycle [30]. These mechanisms can lead to transmission of the virus [31,9] and can be instrumental for initiation of the outbreak. During our study, it has been noticed that pigs are not subjected to any sanitary test prior to slaughter at Muhanzi municipal abattoir because of the lack of qualified personnel and this is an important risk factor, which can contribute to the spread of diseases among pigs raised by local farmers but also a danger for the public health. 


\section{Conclusion}

This study constitutes a first evidence of ASFV infection among slaughtered pigs in Muhanzi slaughterhouse with a probable high infection among pigs from the district of Idjwi located in the South Kivu province, East of DR Congo. This testifies that ASFV may be present in pig farm from this region. Is this therefore recommended to carry out a serosurveillance across the whole region to screen for both ASFV antibodies the viral genome in pigs at farm level and identify any circulating ASFV genotype. Additionally, a strict policy for controlling the healthy status of slaughtered pigsat abattoirs is needed to secure pig farms in the South Kivu province andprevent introduction of new ASFV genotypes from outside.

\section{Acknowledgements}

We acknowledge Mr. Bienfait Mitima lab technician of the Molecular biology and Biochemistry laboratory of Université Evangélique en Afrique for excellent technical assistance.

\section{References}

[1] S. Costard, L. Mur, J. Lubroth, J. M. Sanchez-Vizcaino, and D. U. Pfeiffer, "Epidemiology of African swine fever virus". Virus Res, no.173, 2013, pp. 191-197.

[2] L. K. Dixon, J. M. Escribano, C. Martins, D. L. Rock, M. L. Salas, and P. J. Wilkinson, "Asfarviridae". In: Fauquet, C. M., M. A. Mayo, J. Maniloff, U. Desselberger, and L. A. Ball (eds), Virus Taxonomy, VIIIth Report of the International Committee on Taxonomy of Viruses, 2005, pp. 135-143. Elsevier Academic Press, London.

[3] C. Gallardo, E. Okoth, V. Pelayo, R. Anchuelo, E. Martín, A. Simón, A. Llorente, R. Nieto, A. Soler, R. Martín, S. Arias, and R. Bishop, "African swine fever viruses with two different genotypes, both of which occur in domestic pigs, are associated with ticks and adult warthogs, respectively, at a single geographical site”. J of Gen Virolono. 92, 2011, pp. 432 -444 .

[4] M. Foueré, "Reportage à Madagascar: un pro du porc". http://pigtrop.cirad.fr/subjects/animal husbandry and sustainable practices/reportage a Madagascar un pro du porc.pdf, 2007, (accessed 21.11.18).

[5] C. J. Quembo, F. Jori, W. Vosloo, and L. Heath, "Genetic characterization of African swine fever virus isolates from soft ticks at the wildlife/domestic interface in Mozambique and identification of a novel genotype". Transb and Emerg Dis, vol. 65 , no. 2 , 2017, pp. $420-431$.

[6] Office International des Epizooties (OIE), "WAHID interface animal health information African swine fever" [athttp://web.oie.int/wahis/public.php] site visited on 20/6/2013.2012.

[7] G. Misinzo, E. D. Kwavi, D. C. Sikombe, M. Makange, E. Peter, P. A. Muhairwa, and J. M. Madege, "Molecular characterization of African swine fever virus from domestic pigs in northern Tanzania during an outbreak in 2013". Trop Anim Health Prod, no. 46, 2014, pp.1199-1207.
[8] C. Gallardo, R. Nieto, A. Soler, V. Pelayo, J. Fernández-Pinero, and I. D. Markowska, "Assessment of African swine fever diagnostic techniques as a response to the epidemic outbreaks in Eastern European Union countries": How to improve surveillance and control programmes. J Clin Microbiol.2015, JCM.00857-15.

[9] M. L. Penrith, and W. Vosloo, "Review of African swine fever: transmission, spread and control: review article". J S Afr Vet Assoc.; vol.80, no. 2, 2009, pp. 58-62.

[10] J. M. Sánchez-Vizcaíno, M. Arias, J. Zimmerman, L. A. Karriker, A. Ramirez, and K. J. Schwartz, “African Swine Fever Diseases of swine". 10th ed. United States of America: John Wiley and Sons; 2012, pp. 396-404.

[11] J. M. Sánchez-Vizcaíno, and L. Mur, “African swine fever diagnosis update". DevBiol (Basel).; no.135, 2013, pp.159-65.

[12] J. E. Achenbach, C. Gallardo, E. Nieto-Pelegrın, B. RiveraArroyo, T. Degefa-Negi, M. Arias, and J. M. Sanchez-Vizcaino, "Identification of a new genotype of African swine fever virus in domestic pigs from Ethiopia". Transb and Emer Dis, 2016, https://doi.org/10.1111/tbed.12511.

[13] M. Arias, C. Jurado, C. Gallardo, J. Fernández-Pinero, and J. M. Sánchez-Vizcaíno "Gaps in African swine fever: Analysis and priorities". Transb Emer Dis, 2017, pp. 1-13.

[14] J. M. Escribano, I. Galindo, and C. Alonso, "Antibody-mediated neutralization of African swine fever virus: myths and facts". Virus Res.; 1vol. 73, no. 1, 2013, pp. 101-109.

[15] A. El-Sawalhy, B. Soumaré, S. Nouala, B. Mukanda, H. Wamwayi, and I. G. Ahmed, "African Swine fever". In Pan African Animal Health Yearbook; Interafrican Bureau for Animal Resources, African Union: Nairobi, Kenya, 2011, pp. $16-17$.

[16] B. A. Lubisi, A. D. Bastos, R. M. Dwarka, and W. Vosloo, "Molecular epidemiology of African swine fever in East Africa". Arch of Virol, no.150, 2005, pp. 2439-2452.

[17] K. Vlassenroot, "South Kivu: Identity, territory, and power in the eastern Congo"; RVI Usalama Project 10 South Kivu.2013.

[18] I. R. Dohoo, S. W. Martin, and H. Stryhn, "Veterinary Epidemiologic Research". 2nd ed. VER Inc., Charlottetown, PEI, Canada, 2009, pp. 610.

[19] A. D. Bastos, M. L. Penrith, C. Cruciere, J. L. Edrich, G. Hutchings, F. Roger, E. Couacy-Hymann, and G. R. Thomson, "Genotyping field strains of African swine fever virus by partial p72 gene characterisation". Arch of Virol, no.148: pp. 693-706.

[20] E. O. Abworo, C. Onzere, A. J. Oluoch, V. Riitho, W. Mwangi, J. Davies, S. Blome, , and P. R. Bishop, "Detection of African swine fever virus in the tissues of asymptomatic pigs in smallholder farming systems along the Kenya-Uganda border: implications for transmission in endemic areas and ASF surveillance in East Africa". J of Gen Virol, Vol 98 no 7, 2017, pp. 1806-1814.

[21] J. K, Lichoti, J. Davies, P. P. Kitala, S. M. Githigia, and E. Okoth, "Social network analysis provides insights into African swine fever epidemiology". Prev Vet Med; no.126, 2016, pp.1-10.

[22] L. F. Thomas, R. P., Bishop, C. Onzere, M. T, Mcintosh, and K. A. Lemire, "Evidence for the presence of African swine fever virus in an endemic region of western Kenya in the absence of any reported outbreak". BMC Vet Res; no.12, 2016, pp.192. 
[23] D. K. Atuhaire, M. Afayoa, S. Ochwo, S. Mwesigwa, and F. N. Mwiine, "Prevalence of African swine fever virus in apparently healthy domestic pigs in Uganda". BMC Vet Res; vol 9, 2013, pp. 263.

[24] A. Grenier, "Quel avenir pour la filière porcine au lac Alaotra (Madagascar) »? Thèse méd. vét., université Paul Sabatier, Toulouse, France, 2004, 112 p.

[25] C. Humbert, Etude épidémiologique de la peste porcine africaine dans la région de Marovoay (Madagascar): "Etude de la filière porcine selon une approche participative et étude de prevalence". Thesis. Inedit. 2006, pp.61.

[26] C. Gallardo, A. Soler, R. Nieto, A. L. Carrascosa, and G. M. de Mia, "Comparative evaluation of novel African swine fever virus (ASF) antibody detection techniques derived from specific ASF viral genotypes with the OIE internationally prescribed serological tests". Vet Microbiol, no.162, 2013, pp. $32-43$.

[27] Office International des Epizooties (OIE), "African swine fever. In Manual of diagnostic tests and Vaccines for terrestrial animals". Vol $6^{\text {th }}$, Paris, France: Office International des Epizooties; vol. $6^{\text {th }}, 2008$, pp.1-13.
[28] L. K. Mulumba-Mfumu, J. E. Achenbach., M. R. Mauldin, L. K. Dixon, C. G. Tshilenge, E. Thiry, N. Moreno, E. Blanco, C. Saegerman, E. Lamien, and A. Diallo, "Genetic Assessment of African Swine Fever Isolates Involved in Outbreaks in the Democratic Republic of Congo between 2005 and 2012 Reveals Co-Circulation of p72 Genotypes I, IX and XIV, Including 19 Variants."Viruses, no. 9, 2017, pp. 31, doi: 10.3390/v9020031.

[29] E. Okoth, C. Gallardo, J. M. Macharia, A. Omore, and V. Pelayo, "Comparison of African swine fever virus prevalence and risk in two contrasting pig-farming systems in South-west and Central Kenya”. Prev Vet Med; no.110, 2013, pp.198205.

[30] M. L. Penrith, W. Vosloo, F. Jori, and A. D. S. Bastos, "African swine fever virus eradication in Africa". Virus Res.; vol.173, no. 1, 2013, pp.228-246.

[31] J. M. Haresnape, "African swine fever in Malawi". Tropl Anim Health Prod, vol.16, no. 2, 1984, pp. 123-125. 